\title{
The Role of Emotional Satisfaction with Spouse and Economic Pressure on getting a Divorce in Iran
}

\author{
Maryam Mokhtari \\ Associate professor of sociology in Yasouj university, Iran \\ Mmokhtari@yu.ac.ir
}

\begin{abstract}
The stability of the family system is one of the ideals of Iranian culture and consequently the disintegration of the family is a social disaster. The purpose of this research is to study the role of emotional satisfaction and economic pressure on getting a divorce in Iran. The method of the present research was causal-comparative. In this study, at first 50 women completed the questionnaires in the courts and then 50 women with the same characteristics were selected for the study in accordance with the demographic characteristics of getting divorce women for homogenization in Yasouj city. In this study a researcher-made questionnaire was used for data collection. Face validity was used to determine its validity and Cronbach's alpha method was used to determine its reliability. Data were analyzed using descriptive and inferential statistics (logistic regression). The result was that emotional satisfaction, not economic pressure, increased the likelihood of divorce.
\end{abstract}

Key words: Divorce, Women, Emotional Satisfaction, Economic Pressure, Iran.

\section{Introduction}

Family is one of the most important social institutions. Because it is the basic of social life. According to Iranian-Islamic culture and tradition, the family is considered to be a sacred social center. Therefor collapse of this center is considered as a disgrace. Accordingly, damage to this center of life, whose primary characteristic is intimacy and emotional support, is considered a form of social harm. One of the most important social injuries is divorce, which causes the family to collapse.

Disruption or divorce in families is not new and has been for a long time. During the twentieth century, the increase in population and the growth of industry and urbanization, followed by changes in the cultural value system and even the normative system in many parts of the world, especially in industrial societies, increased the rate of divorce. Statistical findings show that countries of Maldives, Belarus and America has the highest divorce rate in the world ${ }^{1}$. But the phenomenon of divorce is on the rise in other societies, including Iran.

Looking at the divorce status in Iran, statistics show that divorce rates in Iran have been on the rise. Formal statistics of national organization for civil registration about published divorce and marriage in country during $2011-2018$ years are as follows:

1 -https://www.guinnessworldrecords.com/world-records/highest-divorce-rate/ 
Table1: Divorce and marriage statistics across the country during the years 2011 to 2018

\begin{tabular}{|r|l|l|}
\hline Year & Number of Marriage & Number of Divorce \\
\hline 2011 & 874792 & 142841 \\
\hline 2012 & 791656 & 150324 \\
\hline 2013 & 774513 & 155369 \\
\hline 2014 & 724324 & 163569 \\
\hline 2015 & 685358 & 463765 \\
\hline 2016 & 535670 & 136651 \\
\hline 2017 & 608977 & 174597 \\
\hline 2018 & 550565 & 175614 \\
\hline
\end{tabular}

According to the above table, as the rate of marriage declines, divorce rates have increased in the country. Among the provinces of the country, Kohgiluyeh and Boyer Ahmad have had a high jump in divorce rates compared to previous years. So, marriage - to - divorce ratio in the province in 2011 has declined from 10.1 to 4.11 in 2016. This ratio is 6.7 for the whole country in 2011 and 3.42 for 2016. Given what has been said, the rise in divorce in Iran, which has not been complimented by existing culture and does not yet have the necessary grounds for adequate security of divorced women, is considered a social issue.

Divorce-related social research has been conducted widely in Iran, each of which has pointed to different causes of divorce. In Taghipour's (2004) research, social factors such as addiction, close family involvement and class differences were identified as influencing factors on divorce. Ghiasi et al. (2010) referred to the variables of educational differences of couples, age differences of couple, education of women and age of marriage in this regard. Mohsenzadeh et al. (2011) have mentioned two categories of marital dissatisfaction: Premarital factors including inappropriate motivation and forced marriage and post marriage factors, including conflict with spouse family, low presence of husband at home, and continuity of Single Age Communication and violence against spouse. Lahsayezadeh et al. (2013) have obtained variables about causes of divorce such as Employment status of couples, couple's age distance, sexual satisfaction, couple's self-esteem and intervention of families in couple's live. Mokhtari et al. (2014) found that the variables of sexual and emotional satisfaction, pre-marriage cognition of the spouse, loyalty to the spouse were inversely correlated with the tendency toward divorce. Another sociological research is research of Nabavi et al. (2016). Independent variables included expectations, interference with couples 'lives, financial stress, and individualism that were positively associated with couples' tendency to divorce. Another study by Akhoondi and Hemmati (2019) on the contexts of the divorce process indicates the role of coldness in marital relationships, suspicion, intervention of others in their life and economic pressures in getting a divorce. 
Researches in Iran on divorce from a sociological point of view suggests that a range of social factors that can be categorized into relationships within the family and outside the family as well as material and non-material (emotional) issues may contribute to tendency or getting on a divorce. Given the increasing rate of divorce in the country in recent years, it is necessary to determine which factors (material and non-material) play a more decisive role on getting a divorce.

\section{Theoretical framework}

Since the present study focuses on the analysis of the role of both material and nonmaterial variables in rising of divorce phenomenon, the theories of interest as theoretical framework are Collins emotional energy theory and Canger theory.

Collins says: "People provide a level of emotional energy for interaction, which in turn is a level of cultural capital and the power and status that they have in interaction. It also includes their memories of levels of use of emotions and cultural capital that relate to the past" (Turner,2003,151-153). Since the interactive rituals in a primary group are more tangible, the disruption of these interactive rituals can be attributed to the levels of flowing emotional energy in it. In fact, emotional interaction is an important precondition for successful interaction. Emotional cohesion is a result that desirable conversational resources can produce for the individual (Collins, 1998). For Collins the most important emotional component of interactions is positive feelings about others. The feeling of cohesiveness fluctuates from minimal aggression to warm communication and honest and collaborative activity. This emotional energy is known as trust, intimacy and honesty. By achieving this energy in a situation, person has more emotional resources for successful exchange in subsequent interactions(Ibid).

Canger considers divorce from an economic point of view. In his view, difficult economic times in society have detrimental consequences for families, including the possibility of family breakdown and disorganization. Economic exclusion diminishes the positive interactions of couples and leads them to divorce. Economic difficulties among couples that their family interests are not appropriate for keeping of life in standard level, make their marital life unstable and men in these families have more negative interactions (Conger,1900, Cited by Mohebbi,). Canger's view can be analyzed from the point of view of rational choice that humans pursue relationships that are rationally beneficial to them, and that if economic pressure in a relationship (marriage) is high, its continuity is not rational.

Putting these two perspectives together, it can be argued that the role of both material and nonmaterial factors can increase the likelihood of family dissolution. But which one is more powerful in any social context is a question that the current research is pursuing for Iranian society, and in particular in one of its provinces. According to the above theoretical framework, two hypotheses are proposed in this study:

1- There is a significant relationship between emotional satisfaction with the spouse and getting a divorce.

2- There is a significant relationship between economic pressure and getting a divorce. 


\section{Methodology}

The method of the present research was causal-comparative. The population of this study is including Yasouj's married women that are 61813 people according to the census of 2015 . As in this study, two groups of married people who are continuing their normal lives are compared with those who went to court to get a divorce, Classification sampling is performed comparatively. Therefore, at first 50 women completed the questionnaires in the courts and then 50 women with the same characteristics were selected for the study in accordance with the demographic characteristics of getting divorce women for homogenization. In this study a researcher-made questionnaire was used for data collection. Face validity was used to determine its validity and Cronbach's alpha method was used to determine its reliability. Data were analyzed using descriptive and inferential statistics (logistic regression).

\section{Theoretical and operational definition of variables:}

Getting a divorce: Divorce means emancipation from marriage and commitment (Dehkhoda Dictionary). To operationalize this variable, two groups of normal individuals and individuals who went to the court for divorce were assessed at the nominal measurement level as a dependent variable.

Emotional satisfaction with spouse: Satisfaction is acceptance and happiness (Moein, 2003: 1167). Emotional satisfaction with a spouse means satisfying emotional needs in the family and satisfaction with the exchange of feelings and emotions between himself and his spouse. Emotional satisfaction is measured using five variables, namely:

- When I am sad and upset, my husband loves me and gives me comfort.

- My husband increases my love to himself with praise me.

- My husband and I reinforce our emotions by doing things we love to do.

- In my husband's eyes, I feel love and affection for myself.

- I feel there is a great emotional distance between me and my husband.

Economic pressure: economic pressure in this study is the heavy financial pressure imposed by a lack of sufficient income for supporting the family(Ibid,2003). The items used to measure this variable are:

- I have to work for people for the cost of living.

- My husband and I are unable to provide the financial and economic needs of our children and ourselves.

- Most nights when I am falling asleep, I think about how to make a living.

-I can largely afford of Subsistence of myself and my children.

- It is a pity to buy so much for myself or my children.

- We always spend our living expenses through other supports.

- The financial pressures of life are not so great that I cannot take responsibility for myself or my children. 


\section{Findings}

The findings can be described in two descriptive and inferential categories. The subjects ranged in age from 19 to 57 years. The frequency of age group was similar in both women group.

Table 1: Frequency Distribution of Respondents by Emotional Satisfaction from Spouse

\begin{tabular}{|l|l|l|l|l|r|}
\hline \multirow{2}{*}{$\begin{array}{l}\text { Emotional } \\
\text { Satisfaction }\end{array}$} & \multicolumn{2}{|l|}{ Normal } & \multirow{2}{|l|}{$\begin{array}{l}\text { Smotional } \\
\text { Satisfaction }\end{array}$} & \multicolumn{2}{|l|}{ Getting a divorce } \\
\cline { 5 - 7 } & Frequency & Percent & & Frequency & Percent \\
\hline Low & 11 & 22 & Low & 34 & 68 \\
\hline Average & 16 & 32 & Average & 10 & 20 \\
\hline High & 23 & 46 & High & 6 & 12 \\
\hline Total & 50 & 100 & Total & 50 & 100 \\
\hline
\end{tabular}

The table above shows that emotional satisfaction is higher among normal person than getting a divorce person.

Table 2: Frequency Distribution of Respondents by Economic pressure

\begin{tabular}{|l|l|l|l|r|r|}
\hline \multirow{2}{*}{$\begin{array}{l}\text { Economic } \\
\text { pressure }\end{array}$} & Normal & \multirow{2}{|l|}{$\begin{array}{l}\text { Economic } \\
\text { pressure }\end{array}$} & \multicolumn{2}{|l|}{ Getting a divorce } \\
\cline { 4 - 6 } & Frequency & Percent & & Frequency & Percent \\
\hline Low & 20 & 40 & Low & 14 & 28 \\
\hline Average & 22 & 44 & Average & 24 & 48 \\
\hline High & 8 & 16 & High & 12 & 24 \\
\hline Total & 50 & 100 & Total & 50 & 100 \\
\hline
\end{tabular}

The table also shows that people who continue to marry are facing less economic pressure.

Inferential analysis of research findings was performed by logistic regression. 
Table 3: Logistic Regression Model Summary of Emotional Satisfaction Among Getting a divorce and Normal Respondents

\begin{tabular}{|r|r|r|r|r|r|r|}
\hline Variable & B & S.E & Wald & Df & Sig & Exp(B) \\
\hline $\begin{array}{r}\text { Emotional } \\
\text { Satisfaction }\end{array}$ & -0.425 & 0.076 & 30.87 & 1 & 0.000 & 0.65 \\
\hline
\end{tabular}

The results in Table 3 show that the probability of divorce between the two groups is not the same. Emotional satisfaction reduces the likelihood of getting a divorce by $35 \%$.

Table 4: Logistic Regression Model Summary of Economic Pressure Among Getting a divorce and Normal Respondents

\begin{tabular}{|r|r|r|r|r|r|r|}
\hline Variable & B & S.E & Wald & Df & Sig & Exp(B) \\
\hline $\begin{array}{r}\text { Emotional } \\
\text { Satisfaction }\end{array}$ & -0.094 & 0.064 & 2.17 & 1 & 0.141 & 0.910 \\
\hline
\end{tabular}

The results in Table 4 show that the probability of divorce between the two groups is not the same. But given the significant level of this difference in the probability of divorce, it is not statistically significant. So, the probability of divorce is not dependent on economic pressure.

\section{Discussion}

The Modern World Although it has provided more amenities and conveniences to make life easier, at the same time the mental strain of the modern man has increased compared to the pre-modern man. This increase in tensions can be found in the spirit of the capitalist system that has infiltrated many societies - competition and individualism. As a result of individualism, social relations become very fragile and unstable, and they gradually far from each other and diminish their mutual trust.

Throughout the history of the family, it has always been a context for stylizing of human soul. But with the penetration of individualism into this collectivist institution, one can see signs of a life full of accounting, competition and being non emotional with others that are characteristic of secondary relationships in the family environment. Such conditions are troublesome for the survival of the family, so that they can be far more powerful than other destructive factors in the family.

In the present study, findings on the simultaneous role of two variables of emotional satisfaction and economic stress indicated that the family is a context that overcomes economic problems and pressures, it is the lack of emotional relationships and lack of emotional energy that prevent from staying of actor in family relations scene. Emotional satisfaction with the spouse, which is the result of the importance of counterpart in a social scene(family), can have the effect of overcoming economic problems. In fact, when spouses in the family life define the home environment as a place to exchange emotional energy, away from the turmoil of competition and workplace and outside stresses, this emotional energy forces them to sacrifice for economic problems. A married woman who is emotionally satisfied with her husband commits to living together and tolerates financial difficulties. But when there is no emotional satisfaction from the spouse and the spouse takes refuge in her individuality instead of loving within the family, she/ he is at the same time hurting her/his common life. In this conditions, individuals may seek out their own emotional vacuum out of their shared life and readily accept the disintegration of their family life. 
According to obtained results, it can be said that spouses in today's families need skills in conversation, love, and understanding each other as a human being. Even with many divorces that have taken place economically, the economic problem would present itself as a collective problem in the family, if there was emotional satisfaction in the family environment. So with the emotional energy of spouses trying together to reduce the economic problem.

\section{References}

Akhondi, M.B., Hemmati, F. (2019). Study of the backgrounds and contexts of divorce formation (Case study: Mashhad). Studies of cultural and social of Khorasan, Vol.14, No.2. pp. 7-29.

Collins, R. (1998). The sociology of philosophies: A global theory of intellectual change, Printed in the United States of America.

Dehkhoda Dictionary. (1931).

Ghiasi, P., Moin, L., Rona, S. (2010). Investigating the Social Causes of Divorce Among Women Referred to Family Courts in Shiraz, Women and Society, Vol.1, No.3,

Lahsaeezadeh, A., Mardani, M., Hakiminia, B. (2013). Study of Factors Related to Marital Conflicts in Shiraz, Social Sciences Quarterly, Shoshtar Islamic Azad University, Vol.7, No. 4. Pp. 1-18.

Mohebbi, F. (2012). Sociological Explanation of Divorce, Conference of Strategic Thoughts on Women and the Family, Published by Payame- Edalat Publishing, Iran, Tehran.

Moin Encyclopedic Dictionary. (1972).

Mokhtari, M., Mirfardi, A., Mahmodi, E. (2014). A Study of Social Factors Influencing Tendency towards Divorce in Yasouj, Journal of Applied Sociology, Vol.53, No.1. pp.141157.

Mohsenzade, F., Nazari, A.M., Arefi, M. (2011). Qualitative study of factors contributing to marital dissatisfaction and applying for divorce (the case of Kermanshah), Women's Strategic Study, Vol.14. No.53. pp.7-42.

Nabavi, S.A., (2016). Sociological Analysis of Factors Affecting the Attitude of a Woman to Divorce, Socio- Cultural Strategy Quarterly, Vol. 5. No. 20. Pp. 281-295.

Taghipour, Gh. (2004). A Study of Social Factors Affecting Divorce Demand in Sari, MA Thesis, University of Social Welfare and Rehabilitation Sciences, Tehran.

Turner, J.H. (2003). The Structure of Sociological Theory. London: Wad worth Publishing Company.

Yearbook of Demographic Statistics of National Organization for Civil Registration (2011-2017). 